François BÆSPFLUG, Caricaturer Dieu ? Pouvoirs et dangers de l'image

Paris, Éd. Bayard, 2006, 223 p.

\title{
Arnaud Mercier
}

\section{(2) OpenEdition}

\section{Journals}

Édition électronique

URL : http://journals.openedition.org/questionsdecommunication/7382

DOI : 10.4000/questionsdecommunication.7382

ISSN : 2259-8901

Éditeur

Presses universitaires de Lorraine

Édition imprimée

Date de publication : 1 juillet 2007

ISBN : 978-2-86480-829-9

ISSN : 1633-5961

Référence électronique

Arnaud Mercier, «François BEESPFLug, Caricaturer Dieu ? Pouvoirs et dangers de l'image », Questions de communication [En ligne], 11 | 2007, mis en ligne le 01 juillet 2007, consulté le 12 avril 2021. URL : http://journals.openedition.org/questionsdecommunication/7382; DOI : https://doi.org/10.4000/ questionsdecommunication.7382

Ce document a été généré automatiquement le 12 avril 2021. 


\title{
François BESPFLUG, Caricaturer Dieu? Pouvoirs et dangers de l'image
}

Paris, Éd. Bayard, 2006, 223 p.

\author{
Arnaud Mercier
}

\section{RÉFÉRENCE}

François B๕SPFLuG, Caricaturer Dieu ? Pouvoirs et dangers de l'image. Paris, Éd. Bayard, 2006, $223 \mathrm{p}$.

1 Dominicain et professeur d'histoire des religions à la faculté de théologie de Strasbourg, François Bœspflug livre une synthèse très bien faite et documentée des débats internes aux grandes religions sur la question des images en général, et de l'image de Dieu en particulier. L'exposé se veut résolument pédagogique, pour éclairer la polémique qui a émergé avec l'affaire des caricatures parues dans la presse danoise sur le prophète de l'islam, Mahomet. Terminologie impropre, car il s'agissait «en majorité de simples dessins humoristiques ou satiriques » (p. 12).

2 Par ses propres analyses ou en donnant la parole à des intellectuels qui se sont exprimés, l'auteur prend explicitement position, en distribuant appréciations positives ou négatives dans les deux camps. Ainsi relaie-t-il le jugement sur la plupart de ces dessins, même si l'enjeu n'est pas esthétique : «médiocres, stupides et vulgaires » (p. 12). Il refuse la mise sur le même plan de la «violence » graphique et des violences physiques qui en ont découlé : «Affirmer que la pire violence est d'ordre symbolique c'est tout de même tromper son monde. [... ] La défense du Prophète n'excuse pas tant de violence» (p. 15). De même, il revient sur le dessin qui a fait le plus polémique, le plus politique en effet, celui où l'on voit le Prophète coiffé d'un turban en forme de bombe. Interprété comme une assimilation indigne de tous les musulmans au terrorisme, l'auteur conteste cette interprétation qui est « un procès d'intention, s'y rallier est tombé dans un piège » (p. 16). Il cite alors un article de Jeanne Delsaux dans le journal La Croix (« une des réactions les plus intelligentes » à ses yeux) : « Il est clair 
que ce n'est pas Mohammed, mais la perversion de son image par les fanatiques, qui est visée. Il faut apprendre à lire ", et le dominicain d'ajouter son commentaire, en se désolant qu'ait été écartée toute interprétation plus fine, au second degré, selon laquelle cela peut insinuer que "chaque fois que les fondamentalistes appellent au djihad et répandent la terreur, ils défigurent le Prophète en le coiffant d'un turban explosif » (p. 16). C'est peut-être surestimer l'auteur de cette caricature, mais il est certain qu'on peut lire ce dessin comme une interpellation des Musulmans à réfléchir au fait que des actes terroristes sont commis au nom de l'islam, faisant du coup, de la parole du Prophète, un message de haine et de mort. De l'autre côté, François Bœspflug ne donne pas quitus à ceux qui réclament la liberté absolue de tout dire, le refus de toute forme d'autocensure et même «le droit au blasphème » (p. 19).

3 Constatant que beaucoup d'approximations, voire de bêtises, ont été proférées durant cette période tumultueuse, il se propose donc de présenter de façon pédagogique les positions des principales religions, singulièrement des trois monothéismes, sur la question de l'image. Étayée sur une solide bibliographie et des références précieuses, la présentation est limpide et utile, en ces temps désormais de disette concernant la connaissance des religions. D'ailleurs, fin connaisseur de l'histoire des religions, l'auteur souligne que rares sont les cas d'un corps de doctrine intangible dans l'histoire de chacune des religions. Il pointe au contraire la variabilité des positions : «Au sein d'une même religion, la représentation plastique de Dieu (ou du divin) a une histoire, qui peut faire passer cette religion de l'aniconisme [absence d'images matérielles] à l'iconisme, de l'iconophobie à l'iconophilie, quitte à lui faire traverser des crises d'iconomachie [combattre les images], voire d'iconoclasme [destruction des images]» (p. 28). Dans les trois chapitres (un par monothéisme) qui suivent, on trouvera donc d'utiles rappels : l'islam est "plus aniconique et iconophobe iconoclaste» (p. 40); en effet, "le Coran ne contient aucune condamnation formelle des images - rien de vraiment comparable à l'interdiction juive dans le décalogue » (p. 41); toutefois, une telle interdiction se retrouve dans les hadiths, relatant les dires et actes du Prophète. On reproche alors à l'activité artistique, de par sa fonction démiurgique, de faire exister ex nihilo, de rivaliser avec l'activité créatrice de Dieu. De fait, l'islam a toujours interdit la représentation de Dieu et la vénération d'images. En revanche, le Prophète a été représenté, dans des enluminures ottomanes ou persanes notamment. Quant aux caricatures, loin d'être objets d'incompréhension en terre d'islam car contraires à la tradition, elles sont abondamment utilisées, notamment lorsqu'il s'agit de dénoncer l'action ou l'existence même de l'État d'Israël, avec de forts accents antisémites bien plus qu'antisionistes. Suivent des développements tout aussi instructifs et redresseurs de nombreuses légendes ou incompréhensions sur le judaïsme puis le christianisme (où les images divines ont le plus souvent étaient tolérées voire encouragées). Au-delà de l'histoire des débats théologiques, l'auteur conclut son propos sur le christianisme, en soulignant que nos sociétés européennes, depuis la fin du xix siècle, considèrent que "l'image religieuse, fût-ce l'image de Dieu, est comme un patrimoine disponible, un fonds d'archives, sans plus. Chacun en fait ce qu'il veut. Vient le moment où prédomine une sorte de remake, ludique, moqueur, féroce » (p. 148). Et l'auteur de souligner un fait qui explique sans doute l'ampleur des incompréhensions culturelles autour de la polémique sur Mahomet : « Mettre Dieu en scène est en Europe comme un droit acquis depuis les mystères médiévaux. Qui oserait revenir là-dessus?» (p. 151). Le théologien poursuit donc son travail de rétablissement de la vérité, en soulignant que les musulmans ne sont pas en droit de crier au deux poids deux mesures dans la satire sur 
le sacré islamique: «Ils ne croient pas si bien, mais c'est le Dieu des chrétiens qui en fait le plus souvent les frais » (p. 153).

4 Fort de toutes ces connaissances, l'auteur livre ses enseignements de la crise, qui se terminent, cela n'étonnera personne, par l'appel du Pape Benoît XVI, lancé le 20 février 2006 : « Il est nécessaire et urgent que les religions et leurs symboles soient respectés et que les croyants ne soient plus l'objet de provocations blessant leur démarche et leurs sentiments religieux » (pp. 179-180). Mais, au-delà de la défense de la foi par un homme d'église, le livre propose quelques réflexions stimulantes sur cette crise : «Là où la liberté d'expression n'est nullement menacée, il serait irréfléchi et irresponsable de déclencher des crises. L'idée même de faire un test relève de la pure provocation » ( $\mathrm{p}$. 179). Vouloir imposer à d'autres sociétés nos conceptions de la liberté absolue d'expression sur la religion relève de l'utopie et peut même se révéler contreproductif : «Les affaires d'images religieuses peuvent devenir un point d'appui et un levier pour amateurs de bras de fer qui en cherchent et n'ont pas grand-chose à perdre " (p. 159). Utile aussi est de rappeler que d'un point de vue théologique, une religion assurée d'elle-même ne devrait pas avoir grand-chose à craindre des caricatures : «La divinité et ses prophètes sont en tout état de cause très au-dessus de toute moquerie, et l'on ne peut ne pas renoncer à le rappeler, quand on est pasteur ou théologien. Comme l'a dit très justement Michel Kubler : "Il faut commencer par l'essentiel : Dieu lui-même, quelle que soit la manière dont les hommes se réfèrent à lui, n'est pas affecté par les déformations qu'il subit » (p. 167). Et le dominicain de citer l'ancien Mufti de Marseille, Soheib Bencheikh : «Si ce dessin du turban avec la bombe peut ébranler les bases d'une religion vieille de quatorze siècles, c'est que nous ne sommes pas du tout sûrs de nous " (p. 171). Pour conclure, l'auteur en appelle à l'esprit de responsabilité de chacun, faisant l'éloge d'une certaine forme d'autocensure, inhérente au maintien de toute sociabilité rappelle-t-il. Souhaitant le développement d'une histoire iconique de Dieu pluraliste et comparatiste - de façon peu convaincante à nos yeux -, il termine habilement en laissant la parole au journaliste algérien d'Al Watan, le 9 février 2006, à propos de la treizième caricature : «Des enfants courant dans la rue avec des pierres, des enfants hurlant la haine à plein poumons, des enfants en rangs militaires, des adultes vociférant, s'en prenant à des ambassades, brûlant des drapeaux, exigeant la mort des dessinateurs. Voilà la treizième caricature. Celle qui fait le plus de mal aux musulmans » (pp. 193-194).

5 Pour élargir le traitement de cette question, on ne peut que recommander la fréquentation du stimulant ouvrage du célèbre anthropologue Jack Goody, sorti récemment en format de poche, où ce dernier réfléchit aux variations culturelles et historiques des refus ou acceptations des images dans diverses sociétés de la planète: La peur des représentations. L'ambivalence à l'égard des images, du théâtre, de la fiction, des reliques et de la sexualité. (Paris, Éd. La Découverte, 2006 [1997]). 


\section{AUTEURS}

ARNAUD MERCIER

CREM, université Paul Verlaine-Metz 